\title{
PENGARUH KEDISIPLINAN KERJA TERHADAP KINERJA KARYAWAN PADA BANK PERKREDITAN RAKYAT SARANA ARTHA KERTOSONO
}

\author{
Agathon Andreas G; Budi Rahayu; Dwi Juwarni \\ Fakultas Ekonomi - Universitas Kadiri \\ E-mail : budir@unik-kediri.ac.id
}

\begin{abstract}
This study aims to determine and analyze the performance of employees at the Rural Bank Sarana Artha Kertosono. So to that end, this study aims to address the significance of the influence of work discipline on employee performance. In data analysis using descriptive analysis that is filled in distributing items from each variable, then analyzing simple linear regression and testing hypotheses. From the results of testing with simple linear regression, correlation, and determination shows the disciplinary variable (X) has a significant positive effect partially on employee performance (Y) indicated by the value of $\mathrm{R}$ Square which is equal to 0.074 . This figure shows that the work discipline variable $(\mathrm{X})$ used in this regression equation contributes to the performance of employees (Y) $7.4 \%$ while the remaining $92.6 \%$ is influenced by other variables. The basis of the results of this study can be concluded as the performance discipline has a partial and significant effect on the performance of employees in the Rural Bank Sarana Artha Kertosono.
\end{abstract}

Keywords: Work Discipline and Employee Performance

\begin{abstract}
ABSTRAK
Penelitian ini bertujuan untuk mengetahui dan menganalisi kinerja karyawan pada Bank Perkreditan Rakyat Sarana Artha Kertosono. Maka terhadap hal tersebut, penelitian ini bertujuan untuk menujukan signifikansi pengaruh kedisiplinan kerja terhadap kinerjanya karyawan. Di dalam analisa data menggunakan analisisnya deskriptif yang terisi mendistribusi itemnya dari masing-masing variabelnya, lalu mengganalisis regresi linier sederhana dan pengujian hipotesis. Dari hasil pengujian dengan regresi linier sederhana, korelasi, dan determinasi menunjukan variabel kedisiplinan (X) berpengaruh positif signifikan secara parsial terhadap kinerja karyawan (Y) yang ditunjukkan oleh nilai R Square yaitu sebesar 0,074. Angka ini menunjukan bahwa variabel kedisiplinan kerja $(\mathrm{X})$ yang di gunakan dalam persamaan regresi ini memberikan kontribusi terhadap kinerja karyawan (Y) 7,4\% sedangkan sisanya 92,6\% dipengaruhi oleh variabel lain. Dasar dari hasil penelitian ini dapat disimpulkan sebagai kedisiplinan kinerja berpengaruh signifikansi dan positif secara parsial terhadap kinerja karyawan di Bank Perkreditan Rakyat Sarana Artha Kertosono.
\end{abstract}

Kata Kunci : Kedisiplinan Kerja dan Kinerja Karyawan 


\section{PENDAHULUAN}

Organisasi yang baik harus efektif. Untuk mencapai hal tersebut ada beberapa persyaratan yang harus dipenuhi. Salah satunya adalah pemahaman seseorang pimpinan organisasi terhadap dinamika, ancaman maupun peluang pada suatu organisasi. Hal lain yang perlu di perhatikan adalah persaingan organisasi dalam mencapai tujuannya semakin ketat untuk memenangkan persaingan tersebut dapat dilihat dari budaya disiplin kerjanya.

Disiplin merupakan salah satu cerminan tanggung jawab karyawan terhadap tugas yang diberikan. Disiplin juga dapat meningkatkan kinerja (Yunanto, 2017). Penempatan karyawan juga dapat mempengaruhi disiplin kerja karyawan yang merasa cocok dengan posisi yang dia tempati akan lebih menikmati pekerjaan yang dia lakukan.

Penempatan posisi karyawan sesuai dengan posisinya harus melalui analisa yang ilmiah maupun rasional berdasarkan kondisi pekerjaan yang ada (Rahayu \& Ruhamak, 2018). Dampak positif yang di dapat terhadap kejadian tersebut adalah peningkatan semangat kerja dan disiplin kerja terpelihara dengan baik. Organisasi memiliki harapan terhadap produktivitas setiap tenaga kerjanya. Dalam persaingan, organisasi harus punya strategi untuk meningkatkan kinerjanya (Putra, 2014)

Kantor Bank Perkreditan Rakyat Sarana Artha Kertosono adalah salah satu perusahaan yang sangat menerapkan penegakan kedisiplinan kerja kepada setiap karyawannya dan peningkatan pelayanan kepada setiap nasabah - nasabahnya. Adapun pencapain ini di tentukan oleh beberapa factor termasuk didalamnya adalah sifat kedisiplinan kerja setiap karyawannya, komitmen organisasi untuk mempertahankan karyawannya adalah sifatsaling pengertian diantara pimpinan dan karyawannya.

Disiplin sangat dipengaruhi oleh budaya yang telah diterapkan oleh organisasi tersebut. Namun kebanyakan karyawan belum sepenuhnya menyadari bahwa kedisplinan kerja sangat berpengaruh terhadap kemajuan organisasi. Hal ini dapat dipahami karena kebanyakan orang selalu berpendapat kalau pekerjaan akan cepat selesai apabila di awasi dan di perhatikan oleh pimpinannya. Maka dari itu peneliti tertarik untuk melakukan penelitian tentang "Pengaruh Kedisiplinan Kerja Terhadap Kinerja Karyawan Pada Bank Perkreditan Rakyat Sarana Artha Kertosono". 


\section{TINJAUAN PUSTAKA}

\section{Penelitian Terdahulu}

Tabel 1. Penelitian Terdahulu

\begin{tabular}{|c|c|c|c|c|}
\hline No & Nama Peneliti & Judul & $\begin{array}{c}\text { Variabel dan Alat } \\
\text { Analisis }\end{array}$ & Hasil Penelitian \\
\hline 1 & $\begin{array}{l}\text { Tri Widari } \\
(2016)\end{array}$ & $\begin{array}{l}\text { PENGARUH } \\
\text { DISIPLIN DAN } \\
\text { LINGKUNGAN } \\
\text { KERJA } \\
\text { TERHADAP } \\
\text { KINERJA } \\
\text { PEGAWAI }\end{array}$ & $\begin{array}{l}\text { Jenis penelitian: } \\
\text { Kuantitatif } \\
\text { Variabel: } \\
\text { 1. Disiplin } \\
\text { 2. Lingkungan Kerja } \\
\text { 3. Kinerja } \\
\text { Alat Analisis : } \\
\text { Uji validitas instrumen } \\
\text { menggunakan } \\
\text { Confirmatory Faktor } \\
\text { Analyses(CFA), Uji } \\
\text { reliabilitas menggunakan } \\
\text { Cronbach Alpha, Analisis } \\
\text { data dilakukan dengan } \\
\text { menggunakan analisis } \\
\text { regresi linier berganda. }\end{array}$ & $\begin{array}{lr}\text { Disiplin } & \text { dan } \\
\text { Lingkungan } & \text { Kerja } \\
\text { bersama-sama memiliki } & \text { pengaruh } \\
\text { kinerja pegawai Badan } \\
\text { Kepegawaian } & \text { Daerah } \\
\text { Daerah } & \text { Istimewa } \\
\text { Yogyakarta. } & \end{array}$ \\
\hline 2 & $\begin{array}{l}\text { Hendri Azwar } \\
\text { (2015) }\end{array}$ & $\begin{array}{l}\text { PENGARUH } \\
\text { DISIPLIN } \\
\text { KERJA } \\
\text { TERHADAP } \\
\text { KINERJA } \\
\text { KARYAWAN DI } \\
\text { HOTEL GRAND } \\
\text { INNA MUARA } \\
\text { PADANG }\end{array}$ & $\begin{array}{l}\text { Jenis penelitian: } \\
\text { Kuantitatif } \\
\text { Variabel: } \\
\text { 1. Disiplin } \\
\text { 2. Kinerja } \\
\text { Teknik pengambilan } \\
\text { simple random sampling }\end{array}$ & $\begin{array}{l}\text { Terdapat pengaruh } \\
\text { positif dan signifikan } \\
\text { diantara Disiplin Kerja } \\
\text { Terhadap Kinerjanya } \\
\text { Karyawan pada Hotel } \\
\text { Grand Inna Muara } \\
\text { Padang yaitu sebesar } \\
6,8 \% \text {. maka hipotesis } \\
\text { yang diterima adalah } \\
\text { Ha }\end{array}$ \\
\hline 3 & $\begin{array}{l}\text { Jeli Nata Liyas } \\
\text { (2017) }\end{array}$ & $\begin{array}{l}\text { PENGARUH } \\
\text { DISIPLIN } \\
\text { KERJA } \\
\text { TERHADAP } \\
\text { KINERJA } \\
\text { KARYAWAN } \\
\text { PADA BANK } \\
\text { PERKREDITAN } \\
\text { RAKYAT }\end{array}$ & $\begin{array}{l}\text { Jenis penelitian: } \\
\text { Kuantitatif } \\
\text { Variabel: } \\
\text { 1. Disiplin kerja } \\
\text { 2. Kinerja } \\
\text { Alat Analisis: } \\
\text { Regresi Linier sederhana }\end{array}$ & $\begin{array}{l}\text { Disiplin } \\
\text { berpengaruh } \\
\text { terhadap }\end{array}$ \\
\hline
\end{tabular}




\section{Kedisiplinan}

Keiht Davis mengemukakan bahwa "Discipline is management action to organization standarts". Dasar dari pendapatnya Keiht adalah disiplin kerja dapat menggartikan sebagai pelaksanaannya manajemen untuk dapat memperkuat pedoman pedomannya dalam organisasi. A.A Anwar Prabu Mangkunegara (2005:129).

Disiplin yang terbaik mencerminkan besarannya rasa tanggung jawab seorang pada tugas- tugasnya yang memberi. Arti dari ini mendorong gairah kinerja, semangat kerjanya, dan wujudnya ditujukan pada perusahaan. Dan setiap manajernya selalu berusaha agar bisa para bawahan memiliki sifat yang disiplin dengan baik. (Malayu S.P Hasibuan, 2005 : 193).

(Handoko, 2000) menggatakan bahwa arah tujuannya disiplin untuk menghendaki adanya perbaikan kegiatan masa depan, dan bukan sebagai hukuman, sehingga harapan para karyawannya selalu taat aturan dan kebijakan yang suah ada didalam perusahaan, agar nantinya bisa meningkatkan produktivitas perusahaan.

\section{Hambatan Hambatan Kedisplinan}

Adapun hambatan hambatan kerja yang sering terjadi menurut (Dharma, 2000) dalam bukunya "Manajemen Supervisi" adalah sebagai berikut :

a) Melanggar peraturan jam istirahat dan jadwal kerja lain

b) Melanggar peraturan keamanan dan kesehatan kerja

c) Terlambat masuk kerja atau mangkir pada saat jam kerja

d) Bekerja sangat ceroboh ataupun merusak peralatannya, bahan bakunya

e) berkelahi, tidak bisa bekerja team, ataupun perilaku lainnya yang tidak menggenakkan ( usil ) sesama karyawan

f) Terang terangan menunjukan ketidak patuhan, seperti menolak melaksanakan tugas yang seharusnya di lakukan.

\section{Sanksi Pelanggaran Kedisiplinan}

Sanksi pelanggaran kerja adalah hukuman disiplin yang di jatuhkan pimpinan organisasi kepada pegawai yang melanggar peraturan disiplin yang telah diatur pmpinan organisasi. Menurut Veithzal Rivai (2004:405) 


\section{Jenis jenis Kinerja}

Didalam organisasi dikenal tiga jenis kinerja yakni:

a. Kinerja Strategik

Kinerja strategik biasanya berkaitan dengan strategi dalam penyesuaian terhadap lingkungan dan kemampuan dimana suatu organisasi berada.

b. Kinerja Administratif

Kinerja administratif berkaitan dengan kinerja administrasi organisasi.

c. Kinerja Operasional

Kinerja operasional berkaitan dengan efektifitas penggunaan setiap sumber daya yang digunakan organisasi.

\section{Faktor Faktor Kinerja}

Berikut ini 5 faktor yang dapat mempengaruhi kinerja karyawan :

1. Fasilitas Kantor

2. Lingkungan Kerja

3. Prioritas Kerja

4. Supportive Boss

5. Bonus

\section{Pengukuran Kinerja}

Penilaian kinerja yang efektif memerlukan standart kerja yang berkaitan dengan kinerja. Menurut Cascio (1989:213) agar supaya penilaian kerja efektif, maka harus sesuai dengan standart kerja yang bersifat :

1. Relevance (relevansi)

Adanya hubungan yang jelas Antara standart

2. Sensitivity (sensitivitas)

Mengimplikasikan bahwa system

3. Reliability (keandalan)

pimpinan, rekan, maupun bawahan.

4. Acceptability (penerimaan)

Teman sejawat ataupun bawahan.

5. Practically (praktis)

Menggambarkan bahwa instrument - instrument penilaian kinerja mudah dipahami, dimengerti dan digunakan oleh atasan maupun bawahan 


\section{Hubungan Antara Kedisiplinan Dan Terhadap Kinerja}

Dapat menciptakan suasa disiplin kerja yang lebih baik, dari itu membutuhkan adanya sesuatu peraturan ataupun sanksi yang dimana harus ditaati oleh semuakaryawan. Disini perusahaan harustegas dalam memberikan sanksi - sanksi terhadap para karyawan yang melanggar peraturan, yang mana hal itu sangat berpengaruh terhadap peningkatan kinerja.

\section{Kerangka Berpikir}

\section{Gambar 1. Kerangka Berpikir}

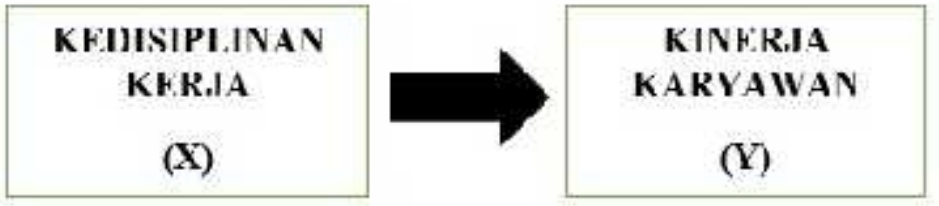

Sumber Ari Wibowo (2014)

\section{METODE PENELITIAN}

Populasi penelitian ini adalah karyawan pada Bank Perkreditan Rakyat Sarana Artha Kertosono. Sampel penelitian diambil dengan menggunakan metode sensus karena jumlah populasi yang tidak terlalu banyak sehingga seluruh jumlah populasi dijadikan sebagai sampel.

Pengumpulan data dilakukan dengan metode angket atau kuesioner dan dokumentasi. Instrumen penelitian diuji dengan uji Validitas dan uji Reliabilitas. Alat analisis data menggunakan regresi linier sederhana dengan pengujian hipotesis melalui uji t dan identifikasi determinasi.

\section{HASIL DAN PEMBAHASAN}

\section{Hasil Uji Validitas}

Tabel 2. Hasil Uji Validitas Butir Instrument Variabel Kedisiplinan Kerja

\begin{tabular}{|l|l|c|c|c|}
\hline \multicolumn{1}{|c|}{ Variabel } & Butir Soal & $r_{\text {hitung }}$ & $r_{\text {tabel }}$ & Keterangan \\
\hline Kedisiplinan & Disiplin 1 & 0,428 & 0,260 & Valid \\
Kerja (X) & Disiplin 2 & 0,825 & 0,260 & Valid \\
& Disiplin 3 & 0,655 & 0,260 & Valid \\
& Disiplin 4 & 0,441 & 0,260 & Valid \\
& Disiplin 5 & 0,825 & 0,260 & Valid \\
& Disiplin 6 & 0,515 & 0,260 & Valid \\
\hline
\end{tabular}

Sumber: Diolah data primer (2018) 
Berdasarkan hasil pengujian validitas pada tabel 1 diketahui seluruh butir pernyataan variabel pelatihan menunjukan nilai $r$ hitung lebih besar dari $r$ table $(0,260)$ dengan nilai terendah 0,428 dan tertinggi 0,825 .

Dengan demikian keseluruhan butir pertanyaan variabel diatas dinyatakan valid dan memenuhi syarat sebagai alat ukur variabel Kedisiplinan Kerja.

Tabel 3. Hasil Uji Validitas Butir Instrument Variabel Kinerja Karyawan

\begin{tabular}{|l|c|c|c|c|}
\hline \multicolumn{1}{|c|}{ Variabel } & Butir soal & $r_{\text {hitung }}$ & $r_{\text {tabel }}$ & Keterangan \\
\hline Kinerja & Kinerja 1 & 0,560 & 0,260 & Valid \\
Karyawan (Y) & Kinerja 2 & 0,589 & 0,260 & Valid \\
& Kinerja 3 & 0,490 & 0,260 & Valid \\
& Kinerja 4 & 0,635 & 0,260 & Valid \\
\hline
\end{tabular}

Sumber: Diolah dari data primer (2018)

Berdasarkan hasil pengujian validitas pada tabel 2 diketahui seluruh butir pertanyaan variabel kinerja karyawan menunjukan nilai $r$ hitung lebih besar dari $r$ tabel $(0,260)$ dengan nilai terendah 0,490 dan tertinggi 0,635 . Dengan demikian keseluruhan butir pernyataan variabel di atas dinyatakan valid dan memenuhi syarat sebagai alat ukur variabel kinerja karyawan.

\section{Hasil Uji Reliabilitas}

Tabel 4. Uji Realiabilitas Variabel Penelitian

\begin{tabular}{|c|c|c|c|c|}
\hline No & ITEM & N. Of Cases & N. Of Item & Cronbach Alpha \\
\hline 1 & Kedisiplinan Kerja (X) & 40 & 6 & 0,675 \\
2 & Kinerja Karyawan (Y) & 40 & 4 & 0,679 \\
\hline
\end{tabular}

Sumber : Diolah dari data primer (2018)

\section{Hasil Uji Regresi Linier}

Tabel 5. Analisis Koefisien Persamaan Regresi Linier Sederhana

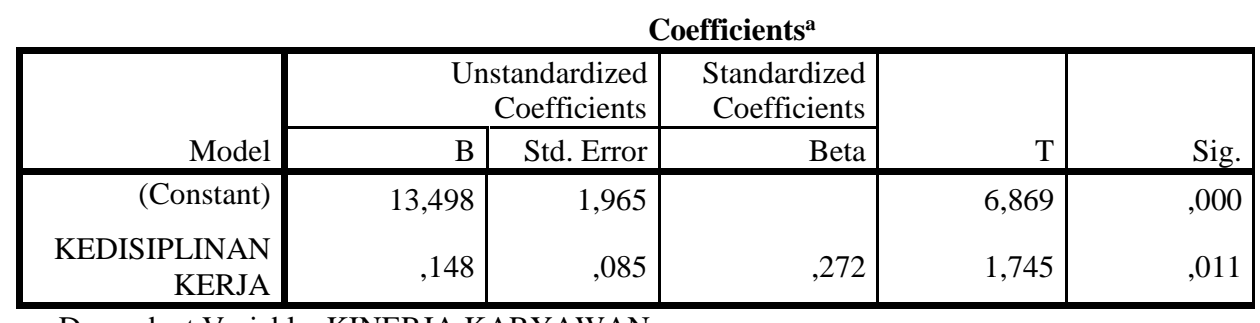

a. Dependent Variable: KINERJA KARYAWAN

Berdasarkan hasil analisis koefisien regresi di atas, maka rumus persamaan regresi linier sederhana adalah:

$$
\mathrm{Y}=13,498+0,148 \mathrm{X}
$$


Persamaan regresi linier sederhana ini dapat diartikan sebagai berikut:

a. Nilai konstanta 13,498 artinya kinerja karyawan Bank Perkreditan Rakyat Sarana Artha Kertosono sebesar 13,498 satuan, dengan ini asumsi kedisiplinan kerja dalam keadaan konstan / tetap.

b. Nilai koefisien regresi kedisiplinan kerja (X) 0,148 tingkat signifikan uji-t (p-value) sebesar 0,011 $(<0,05)$. Hasil ini membuktikan bahwa kinerja karyawan secara signifikan akan meningkat sebesar $14,8 \%$ jika kedisiplinan kerja bagi karyawan Bank Perkreditan Rakyat Sarana Artha Kertosono meningkat 1\%.

\section{Hasil Uji t}

Tabel 6. Koefisien Regresi Untuk Uji t

\begin{tabular}{|c|c|c|c|c|c|}
\hline \multicolumn{6}{|c|}{ Coefficients $^{\mathbf{a}}$} \\
\hline \multirow[b]{2}{*}{ Model } & \multicolumn{2}{|c|}{$\begin{array}{r}\text { Unstandardized } \\
\text { Coefficients }\end{array}$} & \multirow{2}{*}{$\begin{array}{r}\begin{array}{r}\text { Standardized } \\
\text { Coefficients }\end{array} \\
\text { Beta }\end{array}$} & \multirow[b]{2}{*}{$\mathrm{t}$} & \multirow[b]{2}{*}{ Sig. } \\
\hline & B & Std. Error & & & \\
\hline (Constant) & 13,498 & 1,965 & & 6,869 & ,000 \\
\hline $\begin{array}{r}\text { KEDISIPLINAN } \\
\text { KERJA }\end{array}$ & , 148 &, 085 & ,272 & 1,745 & 011 \\
\hline
\end{tabular}

Untuk uji hipotesis pengaruh variabel $\mathrm{X}$ terhadap $\mathrm{Y}$, dapat diinterprestasikan berdasarkan uji probabilitas $t_{\text {-statistik }}$ dengan $t_{\text {-hitung }}(1,745)$ dan sig. sebesar 0.011 yang lebih kecil dari 0,05 yang berarti variabel kedisiplinan kerja berpengaruh signifikan dan postif terhadap kinerja karyawan di Bank Perkreditan Rakyat Sarana Artha Kertosono pada taraf nyata $5 \%$.

\section{Hasil Uji Adjust R Square (Determinasi)}

Tabel 7. Model Summary

\begin{tabular}{|c|c|c|c|c|c|}
\hline \multicolumn{6}{|c|}{ Model Summary ${ }^{b}$} \\
\hline Model & $\mathrm{R}$ & R Square & $\begin{array}{l}\text { Adjusted R } \\
\text { Square }\end{array}$ & $\begin{array}{l}\text { Std. Error of the } \\
\text { Estimate }\end{array}$ & Durbin-Watson \\
\hline 1 &, $272^{\mathrm{a}}$ & ,074 & ,050 & 1,558 & 1,861 \\
\hline
\end{tabular}

Berdasarkan tabel diatas, koefisien $r$ sebesar 0,272 berarti variabel bebas kedisiplinan memiliki hubungan yang erat dengan kinerja karyawan pada Bank Perkreditan Rakyat Sarana Artha Kertosono. Sedangkan R (koefisien determinasi) adalah sebesar 0.074 atau 7,4\%. Ini berarti variabel bebas dapat menjelaskan kinerja karyawan pada Bank Perkreditan Rakyat Sarana Artha Kertosono dengan kontribusi sebesar 7,4\% sedangkan 92,6\% sisanya dipengaruhi oleh variabel lain. 


\section{Pembahasan}

Sumber daya manusia merupakan salah satu modal dasar pembangunan yang terpenting, oleh karena itu tekanan pembangunan mestinya diberikan pada upaya peningkatan kualitas sumber daya manusia, sehingga menjadi sumber daya manusia yang memiliki potensi diri yang unggul baik di bidang sosial maupun lainnya, di harapkan mampu membangun bangsa. Suatu lembaga perusahaan tidak terlepas dari unsur karyawan sebagai pekerja dalam kegiatan belajar. Oleh sebab itu faktor kedisiplinan kerja dan kinerja karyawan yang menjadi faktor utama dalam keberhasilan suatu perusahaan itu sendiri.

Dengan meningkatkan kedisiplinan kerja, maka karyawan dapat mengerjakan tugasnya dengan cepat dan baik, absensi dapat diperkecil seminimal mungkin, bekerja sesuai dengan tugasnya, bertanggung jawab terhadap tugas yang di berikan, hal ini berarti meningkatkan kinerja karyawan. Dengan tingkat kinerja yang tinggi, maka akan membuka kesempatan untuk memperbaiki keada an kerja termasuk jam kerja yang sesuai dengan peraturan. Misalnya berangkat dan pulang kerja sesuai dengan peraturan kantor.

Pada dasarnya kerja yang bermalas malasan atau akan memperlancar kinerja karyawan tersebut. Sebaliknya jika karyawan suatu perusahaan tidak mematuhi peraturan - peraturan yang di terapkan oleh perusahaan maka penerapan kedisiplinan tidak akan terwujud sehingga kinerja tidak dapat ditingkatkan.

Berdasarkan kuesioner yang disebar kepada karyawan Bank Perkreditan Rakyat Sarana Artha Kertosono diketahui untuk variabel bebas (X) kedisiplinan kerja dengan indicator kehadiran, ketaatan pada peraturan dan ketaatan pada standart kerja perusahaan berpengaruh signifikan dan positif secara parsial terhadap kinerja karyawan pada Bank Perkreditan Rakyat Sarana Artha Kertosono. Dengan R square sebesar 0,074 $(7,4 \%)$ dan persamaan regresi sederhana yaitu $\mathrm{Y}=13,498+0,148 \mathrm{X}$. Jadi antara variabel kedisiplinan kerja dan kinerja karyawan di Bank Perkreditan Rakyat Sarana Artha Kertosono ada pengaruhnya yaitu 7,4\% dan 92,6\% lainnya dipengaruhi oleh faktor - faktor lainnya. 


\section{KESIMPULAN}

1. Kehadiran karyawan Bank Perkreditan Rakyat Sarana Artha Kertosono cukup tinggi terbukti $42,5 \%$ responden setuju apabila mereka harus datang tepat waktu jam 8 pagi dan $37,5 \%$ responden mengatakan setuju apabila mereka harus pulang tepat waktu yaitu jam 4 sore.

2. Ketaatan pada peraturan karyawan Bank Perkreditan Rakyat Sarana Artha Kertosono cukup tinggi terbukti 55\% responden mengatakan setuju apabila mereka harus berada di kantor pada saat jam kerja dan 47,5 \% responden mengatakan setuju apabila nereka harus memenuhi peraturan yang ada.

3. Ketaatan pada standart kerja karyawan Bank Perkreditan Rakyat Sarana Artha Kertosono juga cukup tinggi yaitu $42,5 \%$ responden mengatakan setuju apabila mereka harus bertanggung jawab terhadap tugasnya dan $37,5 \%$ responden mengatakan setuju apabila mereka harus bekerja sesuai dengan tugasnya.

4. Dari hasil penelitian atau kuesioner yang disebar kepada karyawan Bank Perkreditan Rakyat Sarana Artha Kertosono diketahui untuk variable bebas (X) kedisiplinan dengan indikator kehadiran, ketaatan pada peraturan dan ketaatan pada standart kerja perusahaan berpengaruh signifikan dan positif secara parsial terhadap kinerja karyawan pada Bank Perkreditan Rakyat Sarana Artha Kertosono. Dengan R square sebesar 0,074 (7,4\%) dan persamaan regresi sederhana yaitu $\mathrm{Y}=13,498+0,148 \mathrm{X}$. Jadi antara Variabel kedisiplinan dan kinerja karyawan di Bank Perkreditan Rakyat Sarana Artha Kertosono ada pengaruhnya yaitu 7,4\% dan 92,6\% lainya dipengaruhi oleh faktor - faktor lainnya.

5. Karena kedisiplinan kerja dan kinerja karyawan pada Bank Perkreditan rakyat Sarana Artha Kertosono sudah baik, maka hal ini perlu di pertahankan dan ditingkatkan.

6. Karena kedisiplinan kerja karyawan pada Bank Perkreditan Rakyat Sarana Arta Kertosono memiliki pengaruh yang kuat terhadap kinerja karyawan Bank Perkreditan Rakyat Sarana Arta Kertosono, maka di harapkan kepada karyawan untuk selalu disiplin dalam bekerja. 


\section{DAFTAR PUSTAKA}

Anoraga, Panji. 2008. Psikologi Kerja. Cetakan Kedua. Jakarta: Penerbit Rineka Cipta. Arikunto, Suharsimi, 2005, Manajemen Penelitian, Cetakan Ketujuh, Jakarta: Rineka Cipta.

Anurogo, Asnawi, 2003, Manajemen Sumber Daya Manusia Perusahaan. Bandung: PT. Remaja Rosda Karya.

Dessler, Garry, 2000, Human Resource Management, New Jersey, Prentice-Hall Inc.

Ghozali, Imam. 2005. Aplikasi Analisis Multivariate dengan program SPSS, Edisi Ketiga, Semarang: Badan Penerbit Universitas Diponegoro.

Gibson, James L. Ivancevich dan Donnely, 1996, Organisasi Perilaku, Struktur Proses, Edisi Pertama, Jakarta: Bina Rupa Aksara.

Gie, The Liang, 2009. Administrasi Modern. Yogyakarta: Liberty

Handoko, T. Hani. 2006. Manajemen Personalia dan Sumber Daya Manusia. Yogyakarta:BPFE

Kusriyanto, Bambang. 2006, Peningkatan Produktivitas Karyawan. Jakarta: CV.

Kurnia Mangkunegara, Anwar Prabu, 2007. Evaluasi Kinerja SDM, Cetakan Ketiga, Bandung: Penerbit Refika Aditama.

Mangkuprawira, Sjafitri. 2003. Manajemen Sumber Daya Manusia Strategik. Cetakan Kedua, Jakarta: PT. Ghalia Indonesia.

Moekijat. 2005. Tata Laksana Kantor. Bandung: Mandar Maju

Mulyasa, E. 2004. Manajemen Berbasis Sekolah, Konsep, Strategi dan Implementasi. Bandung: Remaja Rosdakarya.

Nawawi, Hadari. 2006. Administrasi Personel untuk Peningkatan Produktivitas Kerja. Jakarta: Haji Masagung.

Nazir, Moh. 2003. Metode Penelitian, Cetakan Kelima. Jakarta: Ghalia Indonesia.

Nitisemito, Alex S. 2001. Manajemen Personalia - Manajemen Sumber Daya Manusia. Jakarta: Ghalia

Nitisemito, Alex S. 2003. Manajemen Personalia. Jakarta: Ghalia

Owens, 2001. Organisational Behavior in education. Bonston: Allyn and Bacon.

Putra, Y. P. (2014). Formulasi Strategi Bersaing Pada Universitas Kadiri Dalam Menghadapi Persaingan Antar Perguruan Tinggi Sejenis di Kota Kediri. Universitas Airlangga, Surabaya.

Rahayu, B., \& Ruhamak, M. D. (2018). Pengaruh Kepemimpinan, Insentif, Remunerasi Dan Motivasi Terhadap Kinerja Karyawan (Studi Kasus Pada Pt Industri Sandang Pangan Nusantara Cilacap). Ekonika : Jurnal Ekonomi Universitas Kadiri, 2(1), 122. https://doi.org/10.30737/ekonika.v2i1.15

Yunanto, Y. (2017). Pengaruh Kualitias Peayanan Dan Disiplin Kerja Aryawan Biro Administrasi Umum Terhadap Kepuasan Mahasiswa, 15(2), 99-104.

Ravianto, J. 2005. Produktivitas dan Manajemen. Jakarta: SIUP

Rusel P. 2003. Administrasi Kantor. Jakarta: Bumi Aksara

Saksono, Slamet. 2007. Administrasi Kepegawaian. Yogyakarta: Kanisius

Santoso, Singgih. 2003. SPSS Versi 11 : Mengolah Data Statistik secara Profesional. Jakarta: PT. Elex Media Komputindo.

Sastrohadiwiryo, B. Siswanto. 2002. Manajemen Tenaga Kerja Indonesia. Jakarta: Bumi Aksara

Simanjuntak, J. Payaman. 2005. Pengantar Ekonomi Sumber Daya Manusia. Jakarta: FEUI 
Sinungan, M. B, 2005. Organisasi dan Motivasi. Jakarta: PT. Bumi Aksara Soejono, 2007. Sistem dan Prosedur Kerja. Jakarta: Bumi Aksara Sugiyono, 2006. Statistik Untuk Penelitian. Bandung: Alfebeta.

Westra, Pariata. 2004. Ensiklopedia Administrasi. Penerbit: Gununng Agnung, Jakarta. Yukl, Gary A., 2001. Leadership in Organization. Prentice Hall Inc., New Jersey. Zainun, Buchari. 2004. Manajemen dan Motivasi. Edisi Revisi. Jakarta: Balai Aksara. 